\title{
Migration and genetics of pre-reproductive period in the moth, Spodoptera exempta (African armyworm)
}

\author{
KENNETH WILSON \& A. G. GATEHOUSE \\ School of Biological Sciences, University of Wales - Bangor, Gwynedd LL57 2UW U.K.
}

\begin{abstract}
Migration in insects occurs predominantly, or exclusively, in sexually immature adults. Therefore, the duration of the pre-reproductive period (PRP) sets an upper limit on an individual's migratory potential and has been measured by a number of authors interested in insect migration. Significant differences in PRP between field populations of the African armyworm moth Spodoptera exempta (Walker) (Lepidoptera: Noctuidae) are suggestive of a genetic basis to PRP regulation. The present study examines the genetics of PRP in more detail using selection and sib-analysis experiments. Both sets of experiments suggest a strong genetic component to PRP regulation in female moths, but little or none in males. Moreover, the sib-analysis experiments indicate that the $\mathrm{X}$-chromosome has a disproportionate influence on PRP in females (the heterogametic sex in Lepidoptera). These results are discussed in relation to the migration biology of this species.
\end{abstract}

Keywords: African armyworm moth, migration, pre-reproductive period, reversed response, Spodoptera exempta, X-linkage.

\section{Introduction}

If individuals that breed in the current habitat have lower reproductive success on average than those that disperse to breed elsewhere, then dispersal or migration from the current habitat is always favoured, regardless of its present state (Southwood, 1977; Gatehouse, 1986). Moreover, if long-term average reproductive success is independent of distance travelled, then variation in dispersal ability will be favoured and a genetic polymorphism in dispersal/migratory potential may result (Southwood, 1977). Parker \& Gatehouse (1985; Gatehouse, 1986) have suggested that such genetic variation in migratory potential can be expected in populations of the African armyworm moth (Spodoptera exempta) due to the seasonal pattern of rains in eastern Africa and because successive generations in the same habitat are limited by over-exploitation and disease when densities are high (e.g. Brown \& Swaine, 1965; Blair, 1972; B. Persson, 1980 unpublished report). Wilson \& Gatehouse (in press) have recently demonstrated that, in accordance with the Parker \& Gatehouse hypothesis, there is significant variation in

Correspondence: Dr K. Wilson, School of Biological Sciences, Brambell Building, University of Wales - Bangor, Gwynedd LL57 2UW, U.K. migratory potential both within and between outbreak populations of $S$. exempta. The present study examines the assumption that a substantial proportion of this variation is genetic in origin.

For the majority of night-flying insects, the two most important components of migratory potential are flight capacity (the amount of flight per night) and, because most migration occurs in immature individuals, the pre-reproductive period or PRP (the maximum number of nights' flight) (Johnson, 1969). A number of studies have demonstrated a genetic basis to variation in flight capacity (e.g. Dingle, 1968; Caldwell \& Hegmann, 1969; McAnelly, 1985; Parker \& Gatehouse, 1985). However, until recently, few studies had demonstrated genetic regulation of PRP [but see Derr, 1980; Hegmann \& Dingle, 1982; Colvin, 1990 (J. T. Colvin \& A. G. Gatehouse, unpublished observations); Han \& Gatehouse, 1991; Hill \& Gatehouse, 1992].

Several lines of evidence suggest that migratory potential is genetically regulated in the African armyworm moth. There was a substantial additive genetic component in the tethered-flight performance of laboratory strains of $S$. exempta $\left(h^{2} \geq 0.4\right.$; Parker \& Gatehouse, 1985; see also Woodrow, 1987), and a significant difference between two Kenyan outbreak populations in the proportion of female moths making long (tethered) flights, defined as those lasting at least 
$1 \mathrm{~h}($ Chi-square $=5.11$, d.f. $=1, P<0.05$; data extracted from Gatehouse, 1987, fig. 2; there was no difference between the males). Evidence for the genetic control of PRP in armyworm moths comes from several indirect sources. Parker (1983) and Gunn \& Gatehouse (1987), both found that laboratory strains of $S$. exempta differed in their mean pre-oviposition periods and Page (1988) observed variation between outbreak populations in their mean rates of oocyte development. In addition, Wilson \& Gatehouse (in press) have shown significant differences between 14 outbreak populations of $S$. exempta in the PRPs of both sexes. All of these studies suggest that migratory potential is genetically regulated and that outbreak populations show significant variation in this respect.

Recently, attention has focused on the mode of inheritance of PRP (Colvin, 1990, J. T. Colvin \& A. G. Gatehouse, unpublished observations; Han \& Gatehouse, 1991; Hill \& Gatehouse, 1992) because this has implications for the trait's short- and long-term rates of evolution (Charlesworth et al., 1987; Han \& Gatehouse, 1991). In all three species of noctuid moth, in which the mechanism of PRP inheritance has been examined, a substantial proportion of the variation in female PRP can be attributed to loci on the X-chromosome. In the Oriental armyworm moth, Mythimna separata, female PRP is influenced by loci on both the autosomes and the X-chromosome (Han \& Gatehouse, 1991), and in the cotton-bollworm moth, Helicoverpa armigera, and the silver-Y moth, Autographa gamma, female PRP is regulated predominantly by loci present on the X-chromosome (Colvin, 1990 and Hill \& Gatehouse, 1992, respectively). Both of these latter two species showed significant correlations between the PRPs of brothers and sisters, suggesting that the same genes are involved in both sexes (Colvin, 1990; Hill \& Gatehouse, 1992).

The Parker \& Gatehouse model for migration in $S$. exempta implicitly assumes that migratory potential is under mainly genetic control and that the habitat acts as a template selecting for appropriate phenotypes (and hence genotypes). The present study tests this assumption by quantifying the responses of both sexes to selection for long and short PRPs. It also examines the mode of inheritance of PRP by utilizing a sib-analysis design experiment.

\section{Materials and methods}

\section{Larval and adult environments}

The insects used in both the selection and sib-analysis experiments were the offspring of those collected as late-instar larvae from outbreaks in Tanzania. Those used in the selection experiment were derived from an outbreak in Morogoro, eastern Tanzania, in December 1989 , and those used in the sib-analysis experiment originated from outbreak sites in Sumbawanga district, SW Tanzania, in March 1991.

All larvae were fed an excess of maize leaves each day and reared in a constant environment room $\left(27 \pm 5^{\circ} \mathrm{C}, 52 \pm 8 \% \mathrm{RH}, 13 \mathrm{~L}: 11 \mathrm{D}\right.$ light regime $)$ at densities of 12 per $500 \mathrm{ml}$ glass Kilner jar from the fourth instar onwards (hence all larvae were in the gregaria phase; K. Wilson et al. in preparation). Adult moths were reared under the same ambient conditions and housed separately in $300 \mathrm{ml}$ perspex dishes with netting lids that aided ventilation and allowed the observer a clear view of the insect inside. Except when stated otherwise, moths were fed only distilled water which was provided ad libitum. Observations during the scotophase were made under dim red light $(15 \mathrm{~W}$ bulb at least $50 \mathrm{~cm}$ from the insects).

\section{Assessing the PRP of adult moths}

Following the known pattern of mating behaviour in $S$. exempta (Khasimuddin, 1978; Dewhurst, 1984; Page, 1988), PRP was assessed throughout the latter half of the scotophase from the 'night' of emergence (night 0 or N0) until sexual maturity was indicated. A female was designated mature if she extruded her pheromone gland and began releasing pheromone (i.e. began 'calling'; see Khasimuddin, 1978) or if she attempted to mate with a mature male during a 'challenge', whichever was the earlier. Males were classed as mature if they splayed their claspers in response to a mature female during a challenge. Pheromone release by females was monitored every 10-15 min whilst they were in their dishes. Moths of both sexes were challenged, for up to $5 \mathrm{~min}$ per moth, throughout the scotophase and usually each was challenged only once in a single night. A challenge involved releasing the moth, individually, into a small $(25 \times 25 \times 25 \mathrm{~cm})$ black netting cage, with three or four sexually mature individuals of the opposite sex. Pheromone produced by the moths was dispersed by a small fan blowing air through the cage.

\section{Selection experiment}

The insects used in this study were reared in the same way as those described above, except that half of the moths were fed distilled water alone, whilst the other half were also given four drops $(\sim 0.1 \mathrm{ml})$ of 20 per cent sucrose solution each day. Supplementing the adult diet with a small amount of sucrose solution did not have a consistent effect on the PRPs of males or females in either selected line (Mann-Whitney $U$-tests: $P \geq 0.14)$. The data for these insects were therefore 
combined in the analyses that follow. However, for $3 / 22$ comparisons (within generations and lines; the remainder showed no significant differences), moths fed sucrose solution matured significantly later than those fed distilled water (Mann-Whitney $U$-tests: $P \leq 0.02$ ). This difference is consistent with that for females fed sucrose solution ad libitum, which matured significantly later than those fed distilled water alone (K. Wilson et al. in preparation).

Positive and negative selection were applied to male and female PRP by mating late-maturing males with late-maturing females and early males with early females. Thus, selection was applied to both sexes. After six generations, the selected lines succumbed to viral disease and the experiment ended.

PRP was log-transformed in an attempt to Normalize the data prior to analysis. However, because the transformation failed for all of the male treatment

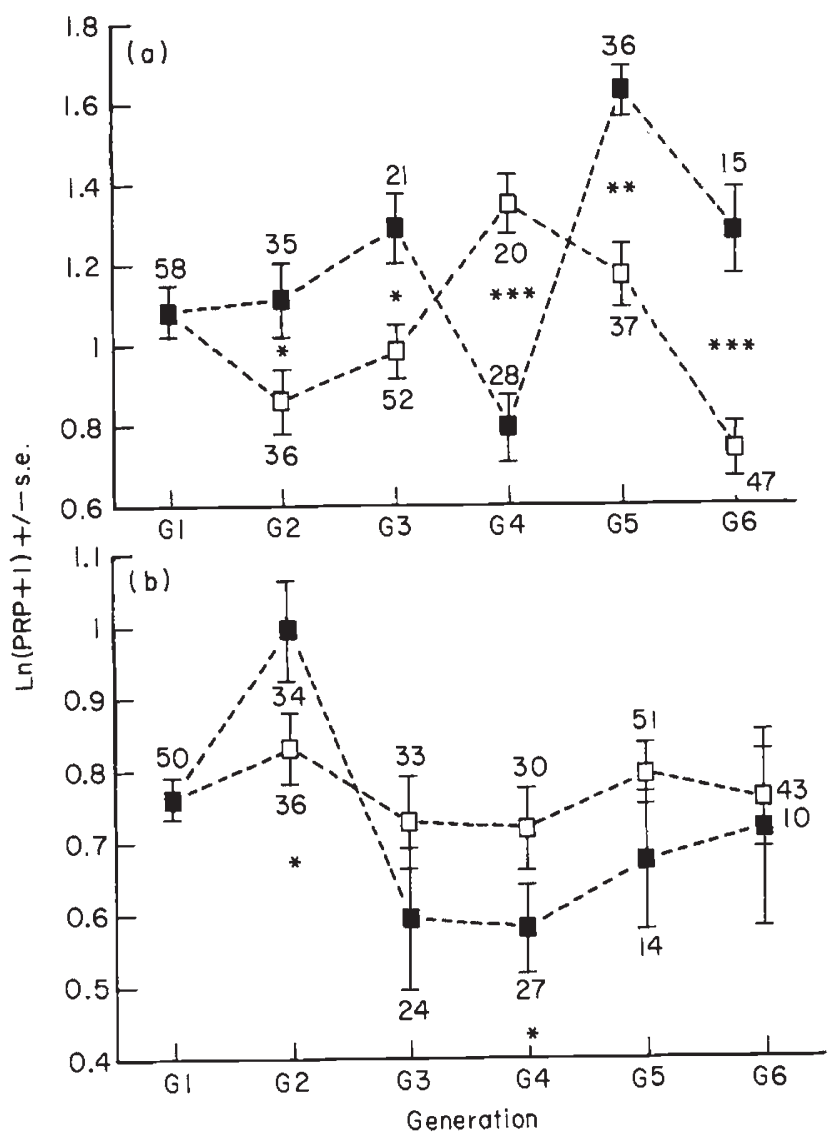

Fig. 1 Selection for early and late maturation in S. exempta. (a) Females; (b) males. Open squares represent mean natural log transformed PRPs for the lines selected for early maturity (short PRP); closed squares for late maturity (long PRP). Numbers next to means are sample sizes. Asterisks indicate significant differences between lines: ${ }^{*} P<0.05,{ }^{* *} P<0.01$, $* * * P<0.001$ groups, the two male lines were also compared using a non-parametric statistical tests. The results of the two sets of analyses were in general agreement.

\section{Sib-analysis experiment}

Females in Lepidoptera are the heterogametic sex and so have one $\mathrm{X}$-chromosome (derived from the male parent) in contrast to the males' two (one from each parent). Therefore, if female PRP is regulated solely by loci on the X-chromosome, then the PRPs of female offspring will be influenced by whichever male is their sire (father) but not by which female is their dam (mother). Conversely, if male PRP is genetically regulated, then both the sire and dam will have a significant influence on the PRP of their male offspring, regardless of whether the loci regulating it are predominantly on the X-chromosomes or the autosomes. By mating each male with at least two females, sib-analysis experiments allow the sires' and dams' contributions to be separated and heritability values to be estimated (Falconer, 1989).

Each of nine males, with PRPs ranging from N1 to N7, were mated to two or three females, each with PRPs ranging from $\mathrm{N} 0$ to $\mathrm{N} 10$. Unfortunately, because of high mortality from viral disease in some families, only the offspring from three sires (eight dams) survived in sufficient numbers to be included in the analyses that follow. PRP was log-transformed prior to analysis in an attempt to Normalize the data. However, the distribution remained skewed towards short PRPs, and therefore the results need to be viewed with some caution.

\section{Results}

\section{Selection experiment}

After a single generation of selection, female PRP differed significantly between the early- and late-maturing lines (Fig. $1 \mathrm{a}$; back-transformed means equal 1.37 and 2.05 nights, respectively: $t=2.08$, d.f. $=69, P<0.05$ ). This difference was maintained in generation G3 $(P<0.05)$ and in all subsequent generations $(P<0.01)$ except $\mathrm{G} 4$, where the direction of the response was reversed; the 'early' line (mean $\mathrm{PRP}=2.85$ nights) maturing significantly later than the 'late' line $(1.22$ nights; $P<0.001)$. This 'reversed response' was apparent $m$ both the water-fed and sucrose-fed treatments and the reason for it is unknown (see Discussion).

In order to quantify the absolute responses to selection on the two lines, regression analyses were performed in which the regression lines were constrained to pass through the mean PRP of the $\mathrm{G}_{1}$ generation. Des- 
pite the reversed responses, PRP increased significantly in the late-maturing line (regression coefficient, $\left.b=0.037 \pm 0.016 ; \quad F_{1,114}=5.41, \quad P=0.022\right) \quad$ and decreased significantly in the early-maturing line $\left(b=-0.031 \pm 0.011 ; F_{1,191}=8.78, P=0.003\right)$ over the five generations of selection. An estimate of realized heritability may be calculated from the weighted regression of divergence response against cumulative selection differential (Falconer, 1989; see Fig. 2a). This yields a heritability estimate of $0.120 \pm 0.023$ s.e. $(t=2.12$, d.f. $=5, P=0.088)$ and, if generation $\mathrm{G}_{4}$ is excluded from the analysis (see Discussion for justification), then $h^{2}=0.161 \pm 0.006(t=11.23$, d.f. $=4$, $P<0.0001$ ).

Male PRP showed little response to selection in either direction (Fig. 1b). After one generation of selection, moths in the early line ( $P R P=1.30$ nights) did mature significantly earlier than those in the late line $(1.70$ nights; $P<0.05)$ but this difference disappeared in the next generation and significantly reversed in the $\mathrm{G}_{4}$ generation $(P<0.05)$. There were no significant differences between the lines in the fifth and sixth generations. Regression analyses indicated that male

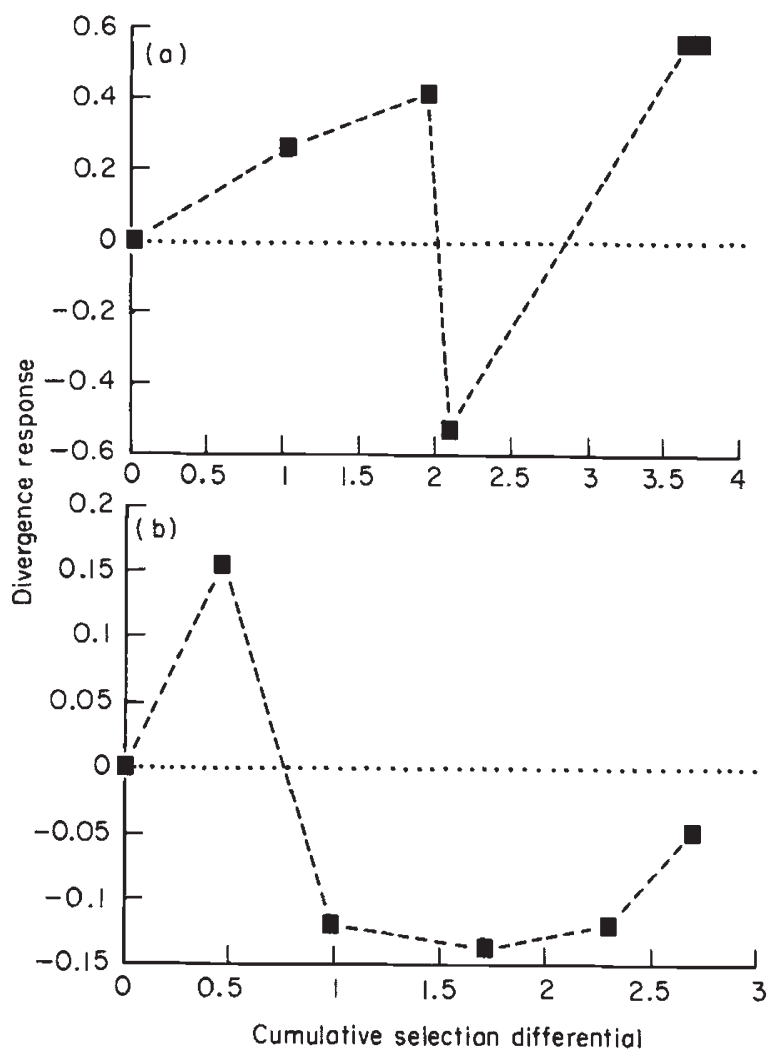

Fig. 2 The divergence response of natural $\log$ transformed PRP to five generations of selection in male and female $S$. exempta. (a) Females; (b) males. For details of selection experiment, see text.
PRP failed to show a consistent response to selection (Fig. 2b).

\section{Sib-analysis experiment}

Although mean PRP of females ranged between 1.40 and 3.33 (a span of nearly two nights), the mean PRP within sires differed by less than one night (Table 1a). Thus, female PRP differed more between sires than dams. This conclusion is confirmed by a nested ANOVA in which the dam and sire components of variance were separated (Table 2). A significant amount of the variation in female PRP was explained by differences between sires $(P<0.02)$, and little by differences between dams $(P>0.27)$. This result is consistent with female PRP being regulated by loci on the X-chromosome alone.

Male PRP differed little between sires or dams (range 1.50-2.10; see Table 1). This result was confirmed by a nested ANOvA (Table 2), although the dam component of variation approached significance $\{0.05<P<0.1\rangle$ due primarily to the late maturation of the male offspring from Dam 6 (Table 1). This result suggests that even if variation in male PRP is under some genetic control the genes involved are not those involved in the regulation of female PRP. The lack of correlation between the PRPs of brothers and sisters ( $\left.r_{\mathrm{s}}=0.060, n=8, \mathrm{~ns}\right)$ supports this view.

Output from the nested ANOvA may also be used to calculate narrow sense heritability estimates (Falconer, 1989). [Standard errors for these means were estimated using the methods for Searle $(1961,1971)$ and Becker (1984) for unbalanced data.] For female PRP, the sire component heritability was estimated as $0.821 \pm 0.767$; the dam component as $0.047 \pm 0.150$, and the overall (sire + dam) heritability as 0.434 \pm 0.380 . These results are consistent with $\mathrm{X}$-linkage but, because of the small number of families available for analysis, the standard errors are very large.

A positive heritability estimate for male PRP cannot be calculated because the between sires mean square is less than the between dams (within sires) mean square (see Falconer, 1989).

\section{Discussion}

\section{Evidence for genetic regulation of PRP}

Three lines of evidence support the contention that female PRP is primarily under genetic control. Firstly, samples of moths collected as larvae from the field, and tested as adults in a common environment, showed significant differences that could not be attributed to 
Table 1 Pre-reproductive period of female and male offspring partitioned between sires and dams

\begin{tabular}{|c|c|c|c|c|c|c|c|c|}
\hline & \multicolumn{3}{|l|}{ Sire 1} & \multicolumn{3}{|l|}{ Sire 2} & \multicolumn{2}{|l|}{ Sire 3} \\
\hline & Dam 1 & Dam 2 & Dam 3 & Dam 4 & Dam 5 & Dam 6 & Dam 7 & Dam 8 \\
\hline \multicolumn{9}{|c|}{ Female offspring } \\
\hline$n$ & 16 & 15 & 15 & 20 & 24 & 21 & 14 & 8 \\
\hline Mean & 3.00 & 3.33 & 2.60 & 1.40 & 2.00 & 1.91 & 2.71 & 2.63 \\
\hline Median & 3 & 3 & 3 & 1 & 2 & 1.5 & 2 & 2 \\
\hline IQR & $2-4$ & $2-4$ & $2-3$ & $1-2$ & $2-3$ & $1-3$ & $1.5-3.0$ & $1.5-3.5$ \\
\hline Range & $1-5$ & $1-8$ & $0-5$ & $0-4$ & $0-4$ & $0-5$ & $0-7$ & $1-6$ \\
\hline \multicolumn{9}{|c|}{ Male offspring } \\
\hline$n$ & 23 & 16 & 29 & 20 & 17 & 21 & 14 & 10 \\
\hline Mean & 1.57 & 1.88 & 1.86 & 1.50 & 1.59 & 2.10 & 1.50 & 1.70 \\
\hline Median & 1 & 2 & 2 & 2 & 1 & 2 & 1.5 & 2 \\
\hline IQR & $1-2$ & $1-2$ & $1-2$ & $1-2$ & $1-2$ & 2 & $1-2$ & $1-2$ \\
\hline Range & $1-4$ & $1-3$ & $0-3$ & $0-3$ & $1-3$ & $1-3$ & $1-2$ & $1-2$ \\
\hline
\end{tabular}

$\mathrm{IQR}=$ interquartile range. Parental PRPs: Sire $1=\mathrm{N} 1$, Sire $2=\mathrm{N} 2$, Sire $3=\mathrm{N} 1$, Dam $1=\mathrm{N} 1$, Dam $2=\mathrm{N} 3$, Dam 3=N2, Dam $4=\mathrm{N} 2$, Dam $5=\mathrm{N} 0$, Dam $6=\mathrm{N} 1$, Dam $7=$ N3, Dam $8=$ N2 .

Table 2 Nested analyses of variance for sib-analyses of natural log transformed PRP in female and male S. exempta

\begin{tabular}{lrrrrr}
\hline Source of variation & \multicolumn{1}{l}{ SS } & d.f. & MS & $F$ & $P$ \\
\hline Female PRP & & & & & \\
$\quad$ Between sires & 3.82 & 2 & 1.91 & 9.44 & 0.020 \\
$\quad$ Between dams (within sires) & 1.01 & 5 & 0.20 & 1.29 & 0.271 \\
$\quad$ Within offspring & 20.57 & 125 & 0.16 & & \\
Male PRP & & & & & \\
$\quad$ Between sires & 0.04 & 2 & 0.02 & 0.12 & 0.894 \\
$\quad$ Between dams (within sires) & 0.85 & 5 & 0.17 & 2.02 & 0.079 \\
$\quad$ Within offspring & 12.00 & 142 & 0.08 & & \\
\hline
\end{tabular}

any environmental factor (Wilson \& Gatehouse in press). Secondly, female PRP responded rapidly to both positive and negative selection: after a single generation of selection there was a significant divergence between the early- and late-maturing lines $(P<0.01)$, which increased over the following four generations $(P<0.001)$. The realized heritability estimates from this experiment $\left(h^{2}=0.120-0.161\right)$ were relatively low, but the standard errors were small. The third line of evidence to support the genetic regulation of female PRP is the sib-analysis experiment, which showed that the sire's genotype had a significant influence on the PRP of its female offspring but that of the dam's did not. The overall heritability estimate for female PRP $\left(h^{2}=0.434\right)$ was relatively large, but the standard error was large also. The importance of the difference between the two heritability estimates is not clear. A high estimate, such as that obtained from the sib-analysis experiment, is expected due to the variable nature of selection through the armyworm season (Ewing, 1979).
The much lower value for realized heritability may therefore by atypical of field populations and reflect the limited amount of variation in the parental $\left(G_{1}\right)$ generation (Fig. 1a).

Evidence that male PRP is genetically regulated is less convincing. Male PRP failed to respond to artificial selection in either direction (except in the first generation of the selection experiment), and the sib-analysis experiment failed to detect any significant maternal or paternal influence on the PRP of male offspring. These results strongly suggest that there is little additive genetic variation in male PRP. However, there were significant differences between samples of males from the field (Wilson \& Gatehouse, in press), which suggests that the lack of any detectable genetical influence on male PRP in these two experiments may be due to the lack of appropriate variation in the experimental insects or to the truncated distribution of male PRP. In the field, nearly 90 per cent $(n=307)$ of males are mature by the end of night 2 , 
compared with just 35 per cent $(n=332)$ of females (Wilson \& Gatehouse, in press). This means that mistakes in the classification of male PRP have much greater consequences for genetic studies than do those in the classification of female PRP. This may also explain the lack of a significant correlation between the PRPs of male and female siblings (see Colvin, 1990; J. T. Colvin \& A. G. Gatehouse, unpublished observations and Hill \& Gatehouse, 1992 for examples of significant correlations). A more thorough analysis is required before a genetic influence on male PRP can be rejected.

\section{Reversed responses in the selection experiment}

Reversed responses (responses opposite to the direction of selection) are relatively common in selection experiments (e.g. Castle \& Wright, 1916; Robertson, 1955; Falconer, 1960; all cited in Gimelfarb, 1986). There are several possible explanations for the reserved responses in the selection experiment of the present study (see Gimelfarb, 1986 for review). One is that they were caused by some environmental factor, such as temperature, which is known to have a negative effect on pre-oviposition period in $S$. exempta (Hattingh, 1941). During the week prior to the start of testing the $\mathrm{G}_{4}$ generation, there was a heat-wave in North Wales and the mean temperature in the experimental room increased from an average of $25-30^{\circ} \mathrm{C}$ and with maxima as high as $32^{\circ} \mathrm{C}$. Because the times of peak emergence of moths from the early and late lines differed by an average of 6 days, the two lines would have experienced the heat-wave at different stages in their development. If there is a critical period during which larval sensitivity to ambient temperature influences PRP, then this could explain the reversed responses.

Another possibility is that the reversed responses were due to random genetic drift. Using a simulation model, Gimelfarb (1986) demonstrated that the probability of this occurring increases as heritability, parental population size, and the proportion of the parental population selected declines. However, in the present study, although the heritability was quite small, the parental $\left(\mathrm{G}_{3}\right)$ populations sizes were fairly large $(52$ and 21 females in the early- and late-lines respectively) and over 70 per cent of females in generation $G_{3}$ were selected as parents (resulting in a small selection differential, see Fig. 2a). This explanation therefore seems unlikely.

A third possibility is that the reversed responses were due to multiplicative genotype-environment (g-e) interactions or other non-additive effects such as dominance, epistasis and maternal effects (Gimelfarb, 1986). A characteristic of g-e interactions is that rever- sals are typically short-lived (Gimelfarb, 1986), as was the case in the present study. If either of these latter two explanations are responsible for the reversed response in the present study, then omission of the $G_{4}$ generation from the analysis may be justified.

\section{$X$-linkage and migration}

The sib-analysis experiment indicates a strong influence of the $\mathrm{X}$-chromosome in the regulation of female PRP. This result is consistent with those from other studies of female PRP in noctuid moths (Colvin, 1990; J. T. Colvin \& A. G. Gatehouse unpublished observations Han \& Gatehouse, 1991; Hill \& Gatehouse, 1992). Based on empirical studies, a number of authors have drawn attention to possible patterns in the evolution of X-linked traits: Thompson (1988) emphasized the importance of the $\mathrm{X}$-chromosome to femalelimited traits in Lepidoptera; Han \& Gatehouse (1991) proposed a special role for $\mathrm{X}$-linkage in the evolution of migration in insects; and Charlesworth et al. (1987) noted that there was some evidence for behavioural traits, in general, being disproportionately affected by the X-chromosome and specifically for traits intimately associated with fitness to be so. Colvin (1990) has recently suggested that PRP comes into this category, along with other traits associated with courtship, mating and reproduction. Clearly, a thorough review of the literature is required to clarify the role of $\mathrm{X}$-linkage in evolution (J. T. Colvin \& A. G. Gatehouse, unpublished observations).

Arguably of greater importance to the study of insect migration is the role of the $\mathrm{X}$-chromosome in the maintainance of genetic polymorphisms. Han \& Gatehouse (1991) suggested that X-linkage in the Oriental armyworm moth, Mythimna separata, reduces the genetic load (Shapiro, 1984) associated with the PRP polymorphism in females, by reducing the frequencies of phenotypes inappropriate to the displacements achieved. Thus, females at the leading edge of this species' migratory range, have the genetic constitution to enable them to return to more hospitable lower latitudes at the end of the summer. The limited empirical evidence supports this genetic partitioning hypothesis: female moths collected from high latitudes $\left(43^{\circ} \mathrm{N}\right)$ matured significantly later than those from lower latitudes $\left(32^{\circ} \mathrm{N}\right)$ (Han \& Gatehouse, 1991).

Outbreaks of $S$. exempta occur on graminaceous crops and grasses throughout the eastern half of subSaharan Africa, from as far north as the Yemen $\left(15^{\circ} \mathrm{N}\right)$ and as far south as South Africa $\left(30^{\circ} \mathrm{S}\right)$. However, nearly one-third of all of these outbreaks occur in Tanzania and Kenya within the latitude range $5^{\circ} \mathrm{N}-10^{\circ} \mathrm{S}$ (Haggis, 1986). Because the availability of 
habitats suitable for larval development is so temporally and spatially variable in this region, and successive generations in the same habitat are penalized (see Introduction), variation in migratory potential will be favoured at every generation (Gatehouse, 1987, 1989). However, long PRPs will generally predominate early in the rainy season when suitable habitats are widely dispersed and, because green areas are widespread and there is little benefit to migrating far, early reproduction (short PRPs) will generally be favoured later in the season. As in $M$. separata, X-linkage will enhance any genetic partitioning between outbreaks that result. But, perhaps more importantly, in the short-term $\mathrm{X}$-linkage may also help to maintain significant genetic variation in the population by lowering the rate of fixation of alleles following directional selection. Whether this is the case depends on several factors, including whether selection acts on one or both sexes, whether there is dosage compensation, on initial allele frequencies, and on the coefficient of dominance (Charlesworth et al., 1987). The importance of X-linkage in the migration biology of $S$. exempta is currently being investigated using genetic simulation models.

\section{Acknowledgements}

We gratefully acknowledge the support and cooperation of the Director-General and staff of the Desert Locust Control Organization for Eastern Africa. We also thank the staff of the Regional Armyworm Programme at DLCO-EA and the Tanzania Ministry of Agriculture, Livestock Development and Cooperatives (Pest Control Services, Arusha) for providing the insects used in this study. We are especially grateful to Mrs Pamela Bower for breeding and rearing the armyworm so successfully for so long and to Dr Gy Ovenden for supplying a computer program to calculate standard errors of the heritability estimates. The insects were maintained in the U.K. under MAFF licence no. PHF 66A and the work was supported under Natural Resources Institute EMC TO153, a component of the ODA Insect Pest Management Initiative Project T0066.

\section{References}

BECKER, w. A. 1984. Manual of Quantitative Genetics 4th edn. Academic Enterprises, Washington.

BLAIR, в. w. 1972. An outbreak of the African armyworm Spodoptera exempta (Walker) (Lepidoptera: Noctuidae) in Rhodesia during December 1971 and January 1972. Rhod. J. Agric. Res., 10, 159-168.

BROWN, E. S. AND SWAINE, G. 1965. Virus disease of the African armyworm Spodoptera exempta (Walker). Bull. Entomol. Res., 56, 95-116.
CALDWELL, R. L. AND HEGMANN, J. P. 1969. Heritability of flight duration in the milkweed bug Lygaeus kalmii. Nature, 223, 91-92.

CASTLE, W. E. AND WRIGHT, s. 1916. Studies of inheritance in guinea pigs and rats. Carnegie Inst. Wash. Publ., 26.

CHARLESWORTH, B., COYNE, J. A. AND BARTON, N. H. 1987. The relative rates of evolution of sex chromosomes and autosomes. Am. Nat., 130, 113-146.

Colvin, J. T. 1990. Migration of the cotton-bollworm moth, Heliothis armigera. Unpublished $\mathrm{PhD}$ thesis, University of Wales.

DERR, J. A. 1980. The nature of variation of life history characters of Dysdercus bimaculatus (Heteroptera: Pyrrhocoridae), a colonising species. Evolution, 34, 548-557.

DEWHURST, C. F. 1984. Some observations on the mating habits of the African armyworm, Spodoptera exempta (Walker) (Lepidoptera: Noctuidae). Entomol. Mon. Mag., 120, 119-125.

DINGLE, H. 1968. The influence of environment and heredity on flight activity in the milkweed bug Oncopeltus. J. Exp. Biol., 48, 175-184.

EWING, E. 1979. Genetic variation in a heterogeneous environment. VII. Temporal and spatial heterogeneity in infinite populations. Am. Nat., 114, 197-212.

FALCONER, D. S. 1960. Selection of mice for growth on high and low planes of nutrition. Genet. Res., 1, 91-113.

FALCONER, D. S. 1989. Introduction to Quantitative Genetics 3rd edn. Longman, London.

GATEHOUSE, A. G. 1986. Migration in the African armyworm Spodoptera exempta: genetic determination of migratory capacity and a new synthesis. In: Danthanarayana, W. (ed.) Insect Flight: Dispersal and Migration. Springer-Verlag, Berlin.

GATEHOUSE, A. G. 1987. Migration and low population density in armyworm (Lepidoptera: Noctuidae) life histories. In: Chaudhury, M. F. B. (ed.) Recent Advances in Research in Tropical Entomology. Insect Sci. Appl., 8 (Special Issue). ICIPE Science Press, Nairobi.

GATEHOUSE, A. G. 1989. Genes, environment and insect flight. In: Goldsworthy, G. J. and Wheeler, C. H. (eds) Insect Flight. CRC Press Inc., Florida.

GIMELFARB, A. 1986. Multiplicative genotype-environment interaction as a cause of reversed response to directional selection. Genetics, 114, 333-343.

GUNN, A. AND GATEHOUSE, A. G. 1987. The influence of larval phase on metabolic reserves, fecundity and lifespan of the African arymworm moth, Spodoptera exempta (Walker) (Lepidoptera: Noctuidae). Bull. Ent. Res., 77, 651-660.

HAGGIS, M. J. 1986. Distribution of the African armyworm, Spodoptera exempta (Walker) (Lepidoptera: Noctuidae), and frequency of larval outbreaks in Africa and Arabia. Bull. Ent. Res., 76, 151-170.

HAN, ER-NING, AND GATEHOUSE, A. G. 1991. Genetics of precalling period in the Oriental Armyworm, Mythimna separata (Walker) (Lepidoptera: Noctuidae), and implications for migration. Evolution, 45, 1502-1510.

HATTINGH, C. C. 1941. The biology and ecology of the armyworm Lyphygma exempta, and its control in South Africa. Dep. Agric. For. South Africa Sci. Bull., 217, 50. 
hegmann, J. P. AND dingle, H. 1982. Phenotypic and genetic covariance structure in milkweed bug life history traits. In: Dingle, H. and Hegmann, J. P. (eds) Evolution and Genetics of Life Histories. Springer-Verlag, New York.

HILL, J. K. AND GATEHOUSE, A. G. 1992. Genetic control of the pre-reproductive period in the silver-Y moth, Autographa gamma (L.) (Lepidoptera: Noctuidae). Heredity, 69, (in press).

JoHnson, C. J. 1969. Migration and Dispersal of Insects by Flight. Methuen \& Co. Ltd, London.

KHASIMUDDIN, s. 1978. Courtship and mating behaviour of the African armyworm, Spodoptera exempta (Walker) (Lepidoptera: Noctuidae). Bull. Ent. Res., 68, 195-202.

MCANELLY, M. L. 1985. The adaptive significance and control of migratory behaviour in the grasshopper Melanoplus sanguinipes. In: Rankin, M. A. (ed.) Migration: Mechanisms and Adaptive Significance, Contrib. Mar. Sci., 27, (Suppl.). Marine Science Institute, Texas.

PAGE, w. w. 1988. Varying durations of arrested oocyte development in relation to migration in the African armyworm moth, Spodoptera exempta (Walker) (Lepidoptera: Noctuidae). Bull. Ent. Res., 78, 181-198.

PARKER, W. E. 1983. An experimental study on the migration of the African armyworm moth, Spodoptera exempta (Walker) (Lepidoptera: Noctuidae). Unpublished PhD thesis, University of Wales.

PARKER, W. E. AND GATEHouse, A. G. 1985. The effect of larval rearing conditions on flight performance in females of the African armyworm, Spodoptera exempta (Walker) (Lepidoptera: Noctuidae). Bull. Ent. Res., 75, 35-47.

ROBERTSON, F. W. 1985. Selection response and the properties of genetic variation. Cold Spring Harbour Symp. Quant. Biol., 20, 166-177.

SEARLE, S. R. 1961. Variance components in the unbalanced 2-way nested classification. Ann. Math. Stat., 32, 11611166.

SEARLE, S. R. 1971. Linear Models. Wiley, New York.

SHAPIRO, A. M. 1984. Experimental studies on the evolution of seasonal polyphenism. In: Vane-Wright, R. I. and Ackery, P. R. (eds) The Biology of Butterflies. Academic Press, London.

SOUTHWOOD, T. R. E. 1977. Habitat, the templet for ecological strategies? J. Anim. Ecol., 46, 337-365.

THOMPSON, J, N. 1988. Evolutionary genetics of oviposition preference in swallowtail butterflies. Evolution, 42, 12231234.

wilson, K. AND GATEhouse, A. G. 1992. Seasonal and geographical variation in the migratory potential of outbreak populations of the African armyworm, Spodoptera exempta. J. Anim. Ecol., 62, (in press).

WOODROW, K. P. 1987. Genetic and environmental factors in the migration of the African armyworm Spodoptera exempta (Walker) (Lepidoptera: Noctuidae). Unpublished PhD thesis, University of Wales. 